EDITORIAL

\title{
The CBANCH Report - The Burden of Neurological Diseases, Disorders, and Injuries in Canada
}

Can. J. Neurol. Sci. 2007; 34: 268-269

\section{NEUROLOGICAL CONDITIONS COST ALMOST \$9 BILLION A YEAR IN Canada}

Conditions associated with longer hospital stays, greater number of years of lost healthy life

June 22, 2007-Neurological diseases, disorders and injuries have a significant economic impact in Canada, costing an estimated $\$ 8.8$ billion in 2000-2001, according to a new report released today. The report, produced by the Canadian Neurological Sciences Federation (CNSF) and the Canadian Brain and Nerve Health Coalition (CBANHC) in collaboration with the Canadian Institute for Health Information (CIHI), used preliminary estimates on the burden of illness from the Public Health Agency of Canada (PHAC). This report is the first of its kind to examine the economic and health-related costs associated with 11 common neurological conditions in Canada: Alzheimer's disease, amyotrophic lateral sclerosis (ALS), brain tumours, cerebral palsy, epilepsy, head injury, headaches, multiple sclerosis, Parkinson's disease, spinal injuries and stroke.

"Neurological conditions affect hundreds of thousands of Canadians, and are among the leading causes of disability in the Canadian population," says Dr. Charles Tator, Chair of the Canadian Brain and Nerve Health Coalition. "Very few neurological conditions are curable, many worsen over time and patients often experience loss of function, accompanied at times with debilitating pain. This represents not just a great burden for patients and their families, but a considerable economic impact for society as a whole."

For example, indirect costs, representing the dollar value of production lost due to long-term disability or premature death, accounted for an estimated $\$ 6.5$ billion in 2000-2001, or almost three-quarters of total costs of the neurological conditions in the study. In comparison, direct costs, including dollars spent on hospital care, physician care and drugs, were estimated at $\$ 2.3$ billion that year.

\section{Alzheimer's disease and stroke carry highest costs}

Among the 11 neurological conditions examined in this study, stroke had the highest direct costs, estimated at $\$ 665$ million in 2000-2001, followed by Alzheimer's disease ( $\$ 431$ million) and headaches (\$411 million). Hospital care expenditures accounted for almost three-quarters (70\%) of the total direct costs for these neurological conditions, while drug expenditures had the second-largest share (20\%) and physician care expenditures made up the smallest proportion $(10 \%)$ of direct costs.

The report also calculated indirect costs for nine of the neurological conditions in the study, and found the largest costs to be associated with stroke (\$2.1 billion), Alzheimer's disease ( $\$ 1$ billion), multiple sclerosis ( $\$ 811$ million) and brain tumours (\$805 million). These nine neurological conditions alone accounted for $8.3 \%$ of the total indirect cost of illness in Canada.

Neurological conditions also affect the health of the population. To quantify this burden, this report includes estimates of disability-adjusted life years (DALYs), a calculation of the years of healthy life lost due to disability or premature death, for six of the neurological conditions highlighted in this report: Alzheimer's disease, epilepsy, headache, multiple sclerosis, Parkinson's disease and stroke.

"These six conditions alone accounted for over 500,000 lost years of healthy life, or $10.6 \%$ of the total DALYs for all illnesses in Canada," says Dr. Tator. "This new information tells us that neurological conditions are not just costly from an economic standpoint, but they also place a heavy burden on the health of the Canadian population as a whole. To put this in perspective, neurological conditions represent a greater burden in terms of lost years of healthy life in Canada than endocrine diseases, respiratory diseases and digestive diseases together."

Patients with neurological conditions have longer-thanaverage hospital stays

In 2004-2005, about 180,000 patients with at least one of the 11 neurological conditions highlighted in this report had to spend at least one night in an acute care hospital in Canada. In fact, 9.3\% of all hospitalizations in Canada were for patients with at least one of these 11 conditions. The median length of stay for patients with a neurological condition was seven days, compared with an overall median of four days for all acute care patients.

Need for additional data on neurological conditions in Canada

The report also notes that there is insufficient data to assess the full impact of these conditions, and CBANHC and its members are calling for more research in this area to provide a more complete picture.

"While this report provides an important first step, we hope it will pave the way for more studies, and serve as a foundation in 
the building blocks toward a better understanding of neurological diseases, disorders and injuries in Canada," says Garth Bray, Vice President of the Canadian Neurological Sciences Federation.

\section{About CNSF}

The Canadian Neurological Sciences Federation (CNSF), formerly the Canadian Congress of Neurological Sciences (CCNS), is an organization representing four member societies: the Canadian Neurological Society, the Canadian Neurosurgical Society, the Canadian Society of Clinical Neurophysiologists and the Canadian Association of Child Neurologists. CNSF's mission is to enhance the care of patients with diseases of the nervous system through education, advocacy and improved methods of diagnosis, treatment and rehabilitation.

\begin{abstract}
About CBANHC
The Canadian Brain and Nerve Health Coalition (CBANHC) is a coalition of several voluntary health organizations, scientists associated with the Canadian Association for Neuroscience and the Institute of Neurological Diseases, Mental Health and Addiction, NeuroScience Canada, and practitioners with an interest in neurological disorders. $\mathrm{CBANCH}$ is committed to improving the quality of life of Canadians by promoting access to cost-effective treatments, supporting research and education and promoting public and government awareness of the incidence and impact of nervous system disorders and injuries. The members of this Coalition plan to use this report to raise awareness for the need for more information and research into neurological diseases, disorders and injuries, as well as for enhanced access to services.
\end{abstract}

Charles Tator, Toronto, Ontario Garth Bray, Ottawa, Ontario Dan Morin, Calgary, Alberta 